This item was submitted to Loughborough's Research Repository by the author.

Items in Figshare are protected by copyright, with all rights reserved, unless otherwise indicated.

\title{
Supplier's total cost of ownership evaluation: a data envelopment analysis approach
}

PLEASE CITE THE PUBLISHED VERSION

http://dx.doi.org/10.1016/j.omega.2015.08.001

PUBLISHER

(C) Elsevier Ltd

VERSION

AM (Accepted Manuscript)

\section{PUBLISHER STATEMENT}

This work is made available according to the conditions of the Creative Commons Attribution-NonCommercialNoDerivatives 4.0 International (CC BY-NC-ND 4.0) licence. Full details of this licence are available at: https://creativecommons.org/licenses/by-nc-nd/4.0/

\section{LICENCE}

CC BY-NC-ND 4.0

\section{REPOSITORY RECORD}

Visani, Franco, Paolo Barbieri, F. Marta L. Di Lascio, Anna Raffoni, and Daniele Vigo. 2015. "Supplier's Total Cost of Ownership Evaluation: A Data Envelopment Analysis Approach". Loughborough University. https://hdl.handle.net/2134/19412. 


\title{
Omega
}

Accepted 2/08/2015 - doi:10.1016/j.omega.2015.08.001

\section{Supplier's Total Cost of Ownership evaluation: a Data Envelopment Analysis approach}

\author{
Franco Visani (Corresponding author) \\ Department of Management \\ University of Bologna \\ Bologna, Italy \\ Paolo Barbieri \\ Department of Management \\ University of Bologna \\ Bologna, Italy \\ F. Marta L. Di Lascio \\ School of Economics and Management \\ Free University of Bozen-Bolzano, \\ Bolzano, Italy \\ Anna Raffoni \\ School of Business and Economics \\ Loughborough University \\ Loughborough, UK. \\ Daniele Vigo \\ Department of Electrical, Electronics and Information Engineering \\ University of Bologna \\ Bologna, Italy
}

\begin{abstract}
Supplier Total Cost of Ownership (TCO) is a widely-known approach for determining the overall cost generated by a supplier relationship, but its adoption is still limited. The complex calculations involved--and in particular the activity-based costing procedure for computing the cost of managing the relationship--pose a major obstacle to widespread TCO implementation. The purpose of this work is to formulate a Data Envelopment Analysis application (denoted 'TCO-based DEA') that can act as a proxy for TCO, and to test its ability to approximate the results of TCO with less effort. The study is based on the analysis of two categories of suppliers (74 in total) of a medium-sized Italian mechanical engineering company. The results show that TCO-based DEA is able to significantly approximate the outcomes of TCO, for both the efficiency indexes and rankings of suppliers, whilst requiring substantially less effort to perform the analysis. To our knowledge, this is the first study to develop a DEA-based tool for approximating TCO and to test it in a realworld setting. The research shows significant potential within the supply chain management field. In particular, TCO-based DEA can be used for analysing suppliers' performance, rationalising and reducing the supplier base, assisting the negotiation process.
\end{abstract}

Keywords: Total Cost of Ownership; Data Envelopment Analysis; Supply Chain Management. 


\section{Introduction}

Total Cost of Ownership (TCO) is a well-known approach for analysing supplier performance (Ellram 1994) - and more specifically efficiency - defined as the total quantity of resources (inputs) that need to be expended to obtain a given quantity of goods or services from a supplier (outputs). TCO takes into account all the activities carried out by a firm to manage a supply relationship. It therefore considers not just the purchase price of a service or good, but also all the other tasks required to do business with that supplier, such as: supplier selection and negotiation, technical analysis and evaluation, order management, quality management, inbound logistics, and administrative processes (Ellram, 1995a). Owing to the ever-expanding role of suppliers in determining firm competitiveness, supplier TCO has received significant attention in both operations research (Ellram and Siferd, 1998; Bhutta and Huq, 2002) and accounting research (Wouters et al., 2005; Van den Abbeele et al., 2009) since the mid 1990s. A variety of TCO models for evaluating suppliers have been proposed (Ferrin and Plank, 2002), and many studies have shown that TCO can effectively support sourcing decisions at different levels (Zachariassen and Arlbjørn, 2011). However, despite its potential utility to supply managers, TCO is still not widely used by manufacturing and service companies (Hurkens et al., 2006). Major barriers to implementing TCO are data availability and the complex activity-based costing procedure needed to quantify the resources devoted to managing each supply relationship. Mapping and costing all the different activities, in particular, is perceived as effort-intensive and time-consuming (Garfamy, 2006). Yet this question of effort, despite being a crucial obstacle to adoption of the method, has not been addressed by the TCO literature, where possible avenues for making TCO more accessible and practicable remain largely unexplored. Instead, recent contributions have focused mainly on improving TCO effectiveness by developing new models, or by proposing the integration of TCO with other tools and frameworks (Degreave et al., 2000; Ramanathan, 2007; Kanagaraj and Jawahar 2009).

This work attempts to fill this gap by developing and empirically testing a tool, denoted 'TCO-based DEA', that can approximate the results of TCO in a more parsimonious way. TCO-based DEA measures the efficiency of the supply relationship by using TCO cost drivers as inputs for Data Envelopment Analysis (DEA), and the purchased amounts as outputs. Thus, TCO-based DEA defines efficiency similarly to TCO, as a ratio of weighted inputs and outputs, but with the notable distinction that TCO-based DEA derives the weights of inputs and outputs from a mathematical programming approach, and so avoids the complex and time-consuming activity-based costing process. In this study we empirically test whether the proposed tool is a valid proxy for TCO by applying it to the case of a medium-sized Italian company that is a global leader in power transmission equipment.

The results show a strong and statistically significant correlation between the efficiency indexes obtained by TCO and TCO-based DEA, while the time needed to perform TCO-based DEA is around $10 \%$ of that required for TCO. Also, since the proposed tool proves particularly effective in detecting the best and worst performers among suppliers, it can usefully assist supply-chain management actions such as negotiation, supply-base reduction, assignment of new components, etc. 
The rest of this paper is organised as follows. Section 2 presents the theoretical framework and the research questions. The specific methodology applied to the analysis of both TCO and TCO-based DEA is described in Section 3, while Section 4 reports the results of the comparison between TCO and TCO-based DEA. Finally, Section 5 discusses the findings and the managerial implications of our research while Section 6 sets out its limitations and potential future developments.

\section{Theoretical background and research objectives}

In the modern business landscape, suppliers are recognised to be major contributors to firm competitiveness (Hopkins, 2010). The pressures of global competition and ever-shorter product life cycles drive companies to focus more closely on their core competencies, reduce operating costs, and pursue higher flexibility by outsourcing activities to subcontractors (Liker and Choi, 2004). As a consequence of this trend, the purchasing share relative to overall sales has risen considerably - to reach nearly $80 \%$, e.g. in the automotive and electronics industries (Van Weele, 2005) - and now frequently includes complex, value-adding components for which the suppliers own part, or most, of the expertise. Supplier performance is thus a key factor determining a company's success or failure (Bhutta and Huq, 2002), and supplier evaluation and selection have become fundamental tasks of the purchasing function (Talluri and Narasimhan, 2004; Jain et al., 2009). Effectively evaluating suppliers, it is argued, requires looking at the overall impact of a supplier's performance on the purchasing firm, to understand the true value the vendor provides (Wouters et al., 2005) and so make better sourcing decisions. Unlike the traditional approach, which focuses primarily on price, more strategic frameworks for evaluating and selecting suppliers consider many factors other than price alone (Ho et al., 2011), thus making the process more complex due to possible conflicts and interactions among the criteria (Sarkis and Talluri, 2002). Frameworks that consider the overall value delivered by suppliers may justify opting for one with a higher purchase price on the grounds of other considerations such as quality, or lower total costs over the long run (Garfamy, 2006) or risk management considerations (RuizTorres and Mahmoodi, 2007; Sawik, 2011).

Effective evaluation and selection of suppliers is regarded as crucial for assisting sourcing decisions in several main streams of modern supply chain management, including strategic supply management, supply base reduction, and international sourcing. Strategic supply management is a long-term, planned effort to create a capable supplier base and establish close relationships (Yeung, 2008). This approach delivers benefits through closer process integration, collaboration in product development, and a stronger level of commitment and trust among the parties (Shin et al., 2000; Lawson et al., 2009; Danese, 2013). However, it also entails increased dependence on suppliers and higher switching costs, which make the consequences of poor partner-selection decisions more severe (de Boer at al., 2001), and in fact empirical evidence shows that firms with a strategic supply management approach are more involved in supplier evaluation (Carr and Pearson, 1999). Supplier evaluation is also relevant to firms with a more conventional supply management approach, when they look to reduce their supplier base to leverage contracting volume effects, simplify purchasing management procedures, or improve inter-firm communication (Minner, 2003). As such firms 
come to allocate business to a smaller pool of suppliers, they must be more careful about selecting the right ones. Finally, effective supplier evaluation and selection is a key aspect of international sourcing, given its higher degree of complexity and risk (Bhutta and Huq, 2002).

The issue of supplier evaluation and selection has been dealt with extensively in the literature, which has considered several evaluation criteria for use by decision-makers, and applied multiple approaches to supplier selection (Ho et al., 2010). A 1991 literature review by Weber et al. found that linear weighting models were the approach most commonly employed. Although such techniques continue to be quite popular in industry, they have been criticised for the subjective manner in which weights are assigned to criteria, and for the difficulty of establishing relative importance when multiple criteria have to be considered (Narasimhan et al., 2001). Since then, a variety of other approaches to supplier selection have been applied, including mathematical programming, analytic hierarchy process (AHP), total cost of ownership (TCO), and data envelopment analysis (DEA), to name a few (Ho et al., 2011). Two separate literature reviews, by Bhutta (2003) and by Ho et al. (2010), found that TCO and DEA were the two most prevalent approaches.

\subsection{Supplier Total Cost of Ownership (TCO)}

TCO is a methodology aimed at "understanding the 'true cost' of doing business with a particular supplier" (Ellram, 1994, p. 171). It endeavours to consider all the costs of managing the relationship with a supplier, rather than looking only at the purchase price. This approach is based on the idea that purchasing decisions affect a wide array of activities done by different departments of the firm (Purchasing, Inbound Logistics, Quality Assurance, Accounting, etc.), which consume resources and generate costs. Therefore, understanding the true cost of dealing with a supplier requires considering all those attendant activities as well as the purchase price. Although TCO is often referred to as a measure of 'supplier performance' (Ellram, 1994), it does not only consider costs arising directly from supplier nonconformities or errors. As many authors have clarified, (Ellram, 1994; Ellram and Siferd,1998; Degreave and Roodhoft, 1999), TCO captures the 'overall' cost of managing a supplier relationship, which involves a multitude of other activities such as supplier selection, order management, delivery arrangements, unpacking, material handling, and administration and accounting issues, to name a few. In other words, a high TCO does not necessarily mean a supplier is at fault (quality issues, poor on-time delivery rate, etc.): it may also be due to other aspects of the supply relationship (e.g. location, inbound logistic facilities, compatibility between different information systems).

Although the idea of 'total cost' is not new (Cavinato, 1991), it has in recent years witnessed an upsurge in importance. Increasing emphasis on the quality of purchased materials and services, rationalisation of supply chains, and global competition have newly highlighted the role of managing purchasing expenditures (Weber et al., 2010; Platts and Song, 2010). In a seminal 1994 paper, Ellram sets out a series of reasons for applying TCO in procurement, which developed into two main research streams on using TCO for internal and external purposes, respectively. Internally, TCO can be used to support supplier-selection decisions, measure ongoing supplier performance, forecast new item performance based on historical data, concentrate resources on 'important few' purchases, compare the performance of suppliers against each other and over time, and 
inform supply-base reduction or volume-allocation decisions (Ellram and Siferd, 1998; Zachariassen and Arlbjørn, 2011; Bhutta and Huq, 2002). Externally, TCO information can be shared with suppliers to drive supplier improvements, negotiate future purchases, and support strategic alliance efforts (Hurkens et al., 2006; Van den Abbeele et al., 2009, Zachariassen and Arlbjørn, 2011). The existing literature has also explored the adoption of TCO for different types of purchases, ranging from goods and services (Degreave et al., 2005; Caniato et al., 2014) to commodities and complex products (Ellarm and Siferd, 1998; Ferrin and Plank, 2002; Zachariassen and Arlbjørn, 2011; Al-Alawi and Bradley, 2013).

TCO analysis is thus applied to a diverse array of procurement situations and decisions, for which various theoretical and practical TCO models have been developed. Among these, we can distinguish between: (1) TCO models designed to help select suppliers for a single component/service (Ellram, 1995a) and models aimed at monitoring suppliers' performance (Carr and Ittner, 1992); (2) standard models applicable to a variety of purchases and custom models specifically developed for a particular type of purchase (Ellram, 1994); (3) models that only consider costs generated by suppliers' deviant behaviour (Monzcka and Trecha, 1998) and models that include all the costs of managing the relationship (Jackson and Ostrom,1980; Ellram, 1994).

In the existing literature, the preferred approach for computing TCO is by activity-based-costing (ABC). Indeed, TCO has sometimes been described as "an application of $\mathrm{ABC}$ concepts and tools to sourcing decisions" (Wouters et al., 2005, p. 167). The importance of ABC for TCO calculations was initially noted by Ellram (1995b), who suggested that ABC was better able to identify low-cost and low-price suppliers than conventional standard-costing or full-costing methods. TCO without $\mathrm{ABC}$ was judged to be of limited value because the methods for allocating costs to suppliers were not clearly traced, and non-quantitative in nature. Subsequent studies further investigated the use of ABC to calculate TCO (Degraeve and Roodhooft, 2000; Degraeve et. al., 2005; Wouters et al., 2005). In particular, Degreave et al. (2000) identified the following advantages of using $\mathrm{ABC}$ for supplier selection models: (1) compared to other methods, $\mathrm{ABC}$ yields more objective cost measures because costs are traced to the activities performed for dealing with a supplier; (2) $\mathrm{ABC}$ makes it possible to calculate the cost impact of different or alternative supplier choices; (3) ABC is able to estimate the consequences of suppliers' performance improvements; (4) ABC can also help evaluate alternative purchasing policies, such as changing the number of suppliers, order quantities, etc.

The ABC approach is able to calculate the costs of the activities involved in the purchasing process, and to allocate those costs based on the effort required to deal with each supplier. The costs of a given activity are therefore allocated only to those suppliers that call for that activity. Applying ABC to calculate TCO usually involves the following main steps: (1) identifying all the activities of the firm related to managing supplier relationships; (2) calculating the total cost of each of those activities; (3) selecting proper cost drivers for allocating activity costs to each supplier; (4) for each supplier, summing all the activity costs allocated to that supplier to obtain the total cost of managing that supply relationship. After completing these steps, each supplier's efficiency is summarised in a Supplier Performance Index (SPI), defined as follows (Timmerman, 1986; Monkcza and Trecha, 1988; Carr and Ittner, 1992): 
Supplier Performance Index $(S P I))_{j}=\frac{\sum_{i=1}^{m}\left(v_{i} * x_{i j}\right)}{y_{j}}$

where $m$ is the number of cost drivers used for the TCO calculation, $v_{i}$ is the unit cost of driver $i, x_{i j}$ is the quantity of driver $i$ ascribed to supplier $j$, and $y_{j}$ is the total purchased amount from supplier $j$. Thus, the SPI quantifies the cost of managing the relationship with a given supplier for one euro of purchased components/services.

Although TCO can offer many benefits, research shows it is still not widespread in practice (Wouters et al., 2005; Hurkens et al., 2006; Zachariassen and Arlbjørn, 2011). A study by Wouters et al. (2005), conducted on a sample of manufacturing and technical service companies, found that many purchasing managers have little experience in applying TCO. Similarly, a study on a sample of US purchasing managers found that $50 \%$ of respondents rated their firm's competencies in measuring TCO as "5" or "lower" on a 1-10 scale (Milligan, 1999). Several explanations have been proposed for the low uptake of TCO in practice. A first obstacle to implementing TCO is the issue of "data availability" (Hurkens et al., 2006; Garfamy, 2006). Performing a TCO analysis requires identifying all the costs affected by purchasing decisions across the company's entire value chain. This in turn requires detailed data about which activities are affected, the costs associated with those activities, and what cost drivers can be identified and used (Degraeve and Roodhooft, 1999). Such a process is typically perceived as time-consuming because firms rarely adopt the ABC method, and their cost information typically focuses on products rather than suppliers as the cost object (Ellram, 1995b). Therefore, significant time and resources are needed to extract and adjust information from existing databases or accounting systems, as well as to collect new data and subsequently maintain the system. Based on an analysis of 11 case studies, Ellram and Siferd (1998) identified "data availability" as one of the chief impediments to adopting TCO.

That said, measurement issues are not the only difficulty in implementing TCO. In fact, the "technology" of any technique is only one of the factors affecting its effectiveness and its potential role within the organization (Orlikowski, 1992, 2000), while human agents and institutional elements (structural arrangements, control mechanisms, business strategies, procedures, etc.) play a major role. The definition and use of TCO, even if "intendedly rational", remains unavoidably heuristic. Cognitive limitations (Simon, 1957) may affect both the design and the use of TCO. The main issue in the development of TCO concerns the understanding of the cause-effect relationships between the management of the supply relationships and the activities performed, thus impacting the selection of the cost drivers. Bounded rationality also affects the selection of the processes to include in the analysis. It often happens that relevant costs driven by the supply relationships are not included in the TCO model, with a clear distortion of the final outcomes. As for the use of the information, common issues regard the interpretation of the results of the TCO analysis: (1) TCO is often interpreted as a measure of supplier efficiency instead of a measure of supply relationship efficiency; (2) casual relationships between managerial decisions and impact on costs included in the TCO are mistaken. 
The misunderstanding of causal relationships in performance measurement (Kasperskaya and Tayles, 2013) and a simplified consequentialism based on PMS adoption (March and Sutton, 1997) are well-known and widely discussed phenomena. Finally, since the total cost concept embraces the overall impact of sourcing decisions, difficulties in the implementation of TCO may arise from the need to involve multiple functional areas such as logistics, manufacturing, and quality assurance, to name a few. Indeed, a study on the adoption of TCO for sourcing decisions shows that senior management support and functional commitment to improved cost information are important factors for the adoption of TCO (Wouters et al., 2005).

\section{$2.2 \quad$ TCO-based DEA}

Data Envelopment Analysis (DEA) is a linear-programming based technique (proposed by Charnes, Cooper and Rhodes in 1978) that is extensively used to assess the efficiency of Decision Making Units (DMUs) in converting multiple inputs into multiple outputs to perform similar tasks. In the last 35 years it has been applied to evaluate the efficiency of very heterogeneous DMUs in complete different fields: from education to healthcare, from management to finance (Liu et al., 2013a), and recent contributions show that research activities relating to DEA are still growing at a very fast rate (Liu et al., forthcoming). As a non-parametric approach, DEA provides a wide family of models which all have in common the proposed efficiency measure of a DMU: an 'efficiency score' defined as the maximum value of the ratio of the weighted sum of outputs to the weighted sum of inputs. For an in-depth analysis and a literature review on DEA, see Cooper et al. (2007); Liu et al. (2013b).

More specifically, the DEA efficiency score is computed as follows. We are given n DMUs (in our case, supply relationships), each of which consumes $m$ inputs and produces s outputs. For each $D M U j=1, \ldots, n$ let $\mathrm{X}_{\mathrm{ji}}$ and $\mathrm{Y}_{\mathrm{jk}}$ respectively denote the non-negative quantity of inputs $\mathrm{i}=1, \ldots, \mathrm{m}$ consumed and of outputs $\mathrm{k}=$ $1, \ldots$, s produced, respectively. Given weighting vectors $\mathbf{V}_{\mathbf{i}}{ }_{\text {and }} \mathbf{U}_{\mathbf{k}}{ }_{\mathbf{k}}$ associated with the inputs and outputs, the absolute efficiency score of a DMU $\mathrm{j}$ is obtained from:

$$
\mathrm{H}_{\mathrm{j}}\left(\mathrm{U}^{\prime}, \mathrm{V}^{\prime}\right)=\frac{\sum_{\mathrm{k}=1}^{\mathrm{s}} \mathrm{U}_{\mathrm{k}}^{\prime} \mathrm{Y}_{\mathrm{jk}}}{\sum_{\mathrm{i}=1}^{\mathrm{m}} \mathrm{V}_{\mathrm{i}}^{\prime} \mathrm{X}_{\mathrm{ji}}}
$$

The problem maximizes the efficiency of that DMU with respect to the other ones. Indeed, "DEA calculates a maximal performance measure for each DMU, relative to all other DMUs in the observed population [...]"(Charnes et al., 1994). An important feature of this method is that the solution to such optimization problems can be efficiently obtained using widely available linear programming solvers.

After computing the absolute efficiency scores for all the DMUs, those with higher efficiency scores are the 'best in-class' and define the efficiency frontier that envelops all other DMUs, which are in their turn defined as inefficient. The dominance of a DMU means there is no other unit in the group with the same output and lower input, and also no other unit with the same input and higher output.

DEA has been extensively employed to analyse the performance of suppliers for selection and control purposes (Narasimhan et al., 2001; Kumar et al., 2014; Ding et al., 2015). A review of 78 papers by Ho et al. 
(2010) shows DEA to be the most popular criterion in the literature on supplier evaluation and selection. The strengths of DEA are considered to be its theoretical robustness, and its flexibility in managing both quantitative and qualitative data (Saen, 2006). On the other hand, as Ho et al. (2010) point out, DEA also has limitations and drawbacks: a) confusion and complexity in defining inputs and outputs; b) subjective assignment of ratings to qualitative criteria; and c) the weighted ratio of inputs to outputs is a measure of efficiency, but is not able to capture suppliers' broader effectiveness.

Our decision to use DEA to define a proxy for TCO was motivated by the fact that, for the purpose of this study, DEA's robustness is not affected by any of the three above-mentioned limitations. Indeed, in our case: a) a clear pattern for defining inputs and outputs is defined; b) qualitative criteria are excluded from the model; and, most importantly, c) the goal is not to capture overall supplier performance, but rather to specifically approximate the efficiency index (SPI) obtained by TCO.

We accordingly devised a DEA model, which we call TCO-based DEA, that computes the efficiency of DMUs (the supply relationships) starting from the same data used in the TCO approach. More specifically, the cost drivers of the TCO framework become the inputs $\mathbf{X}$ of the DEA model, while the total purchased amount (denominator of the SPI) is its only output $\mathbf{Y}$, so that $\mathrm{s}=1$.

Formula (2) thus becomes:

$$
H_{j}\left(U^{\prime}, V^{\prime}\right)=\frac{U_{1}^{\prime} Y_{j}}{\sum_{i=1}^{m} V_{i}^{\prime} X_{j i}}
$$

Comparing the above expression for computing efficiency by the DEA approach (3) with the formula for SPI by the TCO approach (1), we notice a similarity between the two, in that they are both weighted ratios of inputs to outputs. However, the values of the weights ( $\mathrm{V}^{\prime}$ and $\mathrm{U}$ ') used in the DEA model are not arrived at through a time-consuming process, as is instead the case for the SPI. Indeed, the DEA weights are calculated automatically by solving a separate optimisation problem for each individual DMU, in which the weights are decision variables. The application of this TCO-based DEA model to derive the efficiency scores for ranking suppliers is described in Section 3.2.

\subsection{Research objectives}

Given the structural similarities between TCO and DEA, our primary goal in this study was to empirically explore whether TCO-based DEA can act as a proxy for TCO, i.e., to determine whether TCO-based DEA effectively approximates the (difficult-to-measure) supplier efficiency index (SPI) obtained through TCO. This may help the purchasing managers to still take their decisions on the basis of total cost considerations while avoiding the burden of fully-fledged TCO implementation.

Our primary goal was to explore the effectiveness of TCO-based DEA as proxy of TCO over the entire sample of suppliers for the two sourcing categories. In certain cases firms may need to focus on a narrower and more targeted sample for their sourcing decisions. For example, a company might want to single out the best and worst performers (i.e., extreme cases) when considering initiatives for business consolidation, 
supply-base reduction, etc. Accordingly, a second goal of this study was to test TCO-based DEA as a proxy for TCO at the lower and upper extremes of the ranking, i.e., on the suppliers with very low or high efficiencies.

\section{Methodology}

\subsection{Selection of the company and supply categories}

Our empirical analysis focused on two different supply categories of an Italian power transmission equipment company (gear motors, gearboxes, wheel drive applications). To protect confidentiality, the company's real name is not disclosed and we shall refer to it instead as 'Alpha'. Alpha is a medium-sized firm (revenues of nearly $€ 500$ million and 2,400 employees), that operates 7 plants in 5 different countries and has over 1000 active suppliers from 18 countries (mainly Italy, Germany and China). Alpha is one of the leading companies in its industry worldwide, and we selected it for the following reasons:

1. Outsourced work and raw materials account for a very high share of Alpha's total production costs (more than $80 \%$ ), making supplier selection/evaluation a critical issue.

2. Alpha has a wide range of suppliers from many countries and diverse strategic approaches to supply relationships (focus on cost, quality, on-time delivery, innovation), providing multiple ways to absorb activity costs.

3. Alpha has an established Enterprise Resource Planning System (SAP) capable of providing reliable data for each supplier (number of order lines, invoices, quality issues, late deliveries, etc.).

4. The company demonstrated the strongest interest and commitment to the research project, and willingness to share the information needed to conduct the study.

From among Alpha's suppliers, we selected those belonging to two of the largest supply categories: "turning" (50 suppliers, for total purchases of $€ 52.1$ million) and "gearwheels" (24 suppliers, $€ 35.6$ million). Previous studies on supplier TCO have often focused on a single sourcing category and on a small number of suppliers (Degreave et al., 2000; Garfamy, 2006; Hurkens et al., 2006). In this study we instead decided to investigate two of the most populated categories, following the example of Degreave et al. (2005). Turning (a machining process) and gearwheels (a mechanical component) differ substantially from each other in their technical aspects, vendor characteristics, and the manner in which their sourcing is managed. Gearwheels are mostly off-the-shelf components sold by large multinational corporations or distributors. Suppliers in this category are generally interchangeable, except for a small subset of more complex products that demand greater engineering and manufacturing expertise. Turning of components, on the other hand, is a bespoke machining service done to Alpha's specifications. Alpha itself designs the components but may incorporate suppliers' suggestions (e.g., to improve manufacturability). Turning suppliers are generally local SMEs. They may be somewhat interchangeable, insofar as they have similar equipment and technical know-how, but to a lesser extent than gearwheel suppliers. Also, since Alpha usually collaborates with its turning suppliers on product engineering, switching to a different supplier may entail duplicating the costs of the 
product-engineering phase. The two supply categories also absorb operational activities very differently, thus presenting distinct total cost structures. Turning suppliers usually generate a great many activities, especially pertaining to quality management and new product development, while gearwheel suppliers are much more straightforward to manage. The number of categories analysed in this study as well as the total number of suppliers included is aligned with previous contributions that have applied DEA to supplier evaluation (Liu et al., 2000; Narasimhan et al., 2001; Wu and Blackhurst, 2009).

\subsection{TCO and DEA development}

To obtain the basis for comparison, we performed the TCO procedure to calculate the SPI of each supplier included in the study, following the activity-based costing approach presented in Section 2.1. We began with a focus group comprising the chief operating officer (COO) and the heads of the five departments involved in managing supplier relationships (Purchasing, Logistics, Engineering, Quality Assurance and Accounting). The focus group identified four main macro-processes involved in sourcing (new product development, order definition and management, inbound logistics, and quality analysis and management) and the department heads drew up an initial, general list of activities relating to those macro-processes. The people to interview were then selected based on the following criterion: for activities done by only one employee, he/she was interviewed, while for activities done by several employees two (chosen at random) were interviewed. Following this approach, we selected 87 interviewees out of the 239 employees working in the five departments.

We then carried out in-depth interviews with the selected employees and the department heads to obtain a more fine-grained description of the activities and tasks performed, which yielded a final detailed list of 57 activities. The next step was to calculate the time and cost absorbed by each activity. For recurring activities with a standard output (order or invoice data entry, order plan definition, quality checking, etc.), we obtained a standard time by clocking employees as they did the activity. For stand-alone activities with a non-standard output (negotiations with suppliers, management of quality issues, etc.) we asked employees to estimate the time as a percentage of their total annual time. The time spent on each activity was multiplied by the average employee hourly cost to obtain the total annual cost of that activity. This total annual activity cost has three components: gross salary; cost of equipment and services used by employees (buildings, energy, cars, forklifts, etc.); and allocated costs of auxiliary departments (HR, Information Systems department, etc.). The total cost computed for the 57 identified activities was $€ 13.9$ million.

The final step in the procedure was to identify the cost drivers for allocating the cost of each activity to the suppliers. We asked the five department heads to explain what quantifiable factors influence the complexity of a supply relationship and the amount of each activity that it requires. This resulted in six activity cost drivers being identified, and for each of these we asked the Information Systems department to extract the data pertaining to each supplier. The six activity cost drivers defined were: quality issues (to allocate the cost of 21 activities; $€ 4.2$ million); late deliveries ( 5 activities; $€ 693,000$ ); number of samplings done ( 2 activities; $€ 253,000$ ); pallets received (6 activities; $€ 2.7$ million); order lines (20 activities, $€ 1.2$ million); pallets 
delivered to suppliers (mainly transportation costs for contract work; 4 activities worth $€ 4.8$ million). To validate the overall TCO model (process, activities, costs and cost drivers), we interviewed the controllers of Alpha's two principal competitors. Apart from slight differences in the supply chain structure (one of the competitors externalises a greater portion of the total value), those firms confirmed that the activities identified during the interviews at Alpha are likewise the most relevant in their own purchasing process, and that the main cost drivers are the same.

Finally, we added all the activity costs allocated to each supplier to determine the total cost of managing that relationship. We then divided this amount by the total purchased amount from the supplier to calculate that supplier's SPI.

Table 1 summarises the main steps of the TCO analysis and the time taken to perform them while Figure 1 represents the flow of resources from input cost values to the final cost driven by each cost driver.

\section{Table 1. The steps of the TCO process}

\begin{tabular}{|c|c|c|c|c|c|c|c|c|}
\hline \multirow{2}{*}{ N. } & \multirow{2}{*}{ Step } & \multirow{2}{*}{ Output } & \multicolumn{2}{|c|}{ Employees } & \multicolumn{2}{|c|}{ Researchers } & \multicolumn{2}{|c|}{$\begin{array}{l}\text { Total people } \\
\text { involved }\end{array}$} \\
\hline & & & $\begin{array}{c}\text { People } \\
\text { involved }\end{array}$ & $\begin{array}{l}\text { Total } \\
\text { work } \\
\text { hours } \\
\end{array}$ & \begin{tabular}{|c|} 
People \\
involved
\end{tabular} & $\begin{array}{l}\text { Total } \\
\text { work } \\
\text { hours }\end{array}$ & $\begin{array}{c}\text { People } \\
\text { involved }\end{array}$ & $\begin{array}{l}\text { Total } \\
\text { work } \\
\text { hours }\end{array}$ \\
\hline 1 & $\begin{array}{l}\text { Focus group with the } \mathrm{COO} \text { and the } \\
\text { heads of the departments involved } \\
\text { in the relationship with the supplier }\end{array}$ & $\begin{array}{c}\text { Processes to } \\
\text { analyze and } \\
\text { people to } \\
\text { interview } \\
\end{array}$ & 6 & 24 & 2 & 8 & 8 & 32 \\
\hline 2 & $\begin{array}{l}\text { Interviews with the heads of the } \\
\text { departments and with the selected } \\
\text { employees }\end{array}$ & $\begin{array}{l}\text { List of activities } \\
\text { and related times } \\
\text { and costs }\end{array}$ & \begin{tabular}{|c|}
$92(5$ \\
directors \\
+87 \\
employe \\
es $)$ \\
\end{tabular} & 388 & 3 & 490 & 95 & 878 \\
\hline 3 & $\begin{array}{l}\text { Selection and analyisis of the } \\
\text { activity cost drivers, calculation of } \\
\text { SPI. }\end{array}$ & SPI & 8 & 29 & 1 & 20 & 9 & 49 \\
\hline & Total & & 106 & 441 & 6 & 518 & 112 & 959 \\
\hline
\end{tabular}

Figure 1. The resource flow from the management accounting to the final costs driven by each cost driver 


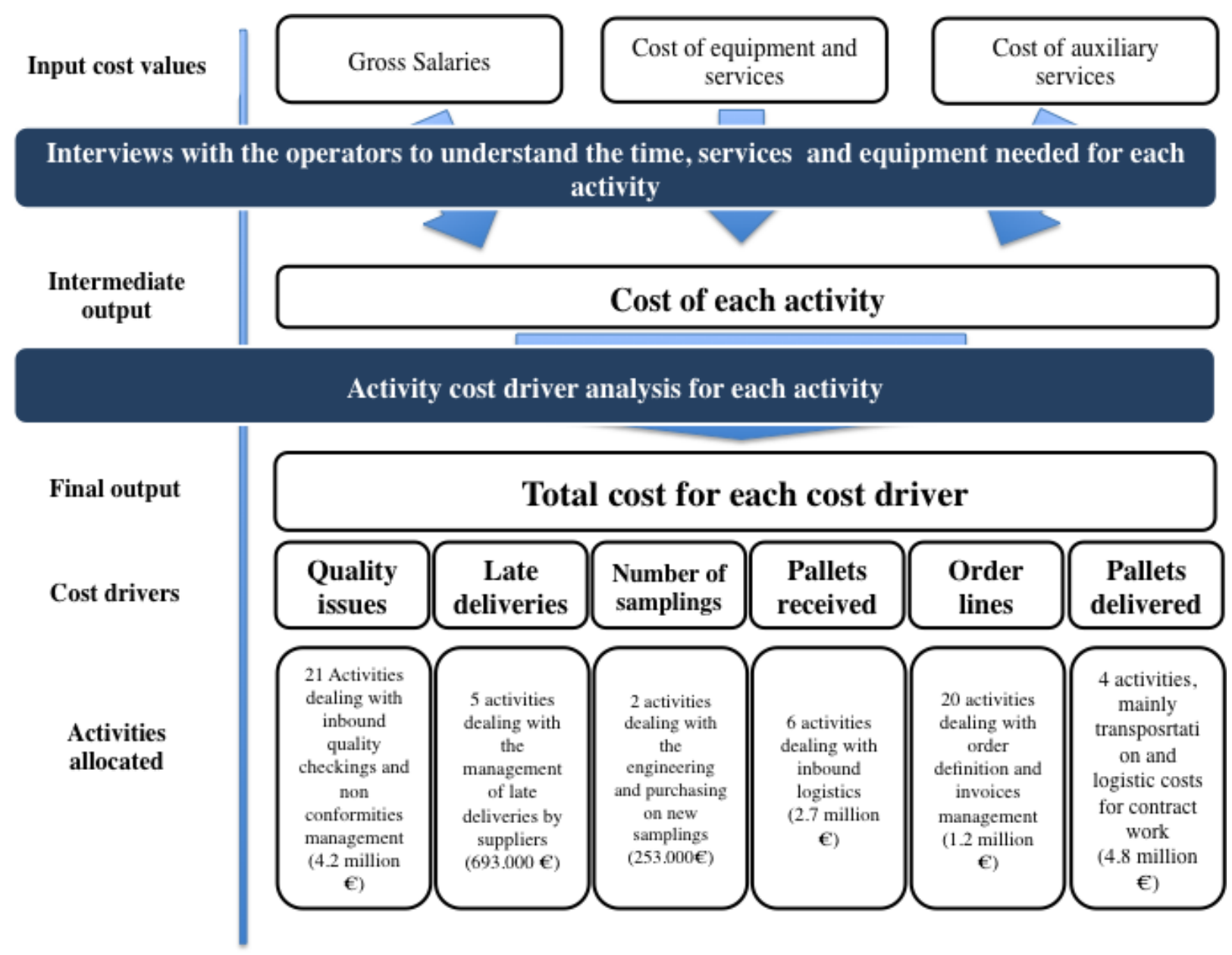

The SPI values obtained ranged from $0.03 \%$ to $8 \%$ for "gearwheels" suppliers, and from $0.6 \%$ to $26 \%$ for "turning" suppliers.

After completing the TCO procedure, we defined a DEA-based proxy according to the pattern set out in Section 2.2. We used the six cost drivers of the TCO model as the inputs of the DEA model, and set the purchased amount (denominator of the SPI) as its single output. The specific DEA implementation we chose was an input-oriented version of the standard CCR model (see Charnes et al., 1994). We also did some preliminary testing with alternate DEA formulations---such as the BCC model (Banker et al., 1984), which explicitly takes into account scale factors in the efficiency evaluation--which yielded comparable results to those presented below.

More specifically, the linear programming model to solve to evaluate the efficiency $\mathrm{H}_{\mathrm{j}_{0}}$ of supplier $\mathrm{j}_{0}$ is the following:

$$
\mathrm{H}_{\mathrm{j}_{0}}=\max \mathrm{U}_{1}^{\prime} \mathrm{Y}_{\mathrm{j}_{0}}
$$

subject to the conditions: 


$$
\begin{array}{cc}
\mathrm{U}_{1}^{\prime} \mathrm{Y}_{\mathrm{j}}-\sum_{\mathrm{i}=1}^{\mathrm{m}} \mathrm{V}_{\mathrm{i}}^{\prime} \mathrm{X}_{\mathrm{ji}} \leq 0 & \forall \mathrm{j}=1, \ldots, \mathrm{n} \\
\sum_{\mathrm{i}=1}^{\mathrm{m}} \mathrm{V}_{\mathrm{i}}^{\prime} \mathrm{X}_{\mathrm{j}_{0} \mathrm{i}}=1 & \\
\mathrm{U}_{1}^{\prime}, \mathrm{V}_{\mathrm{i}}^{\prime} \geq \varepsilon & \forall \mathrm{i}=1, \ldots, \mathrm{m}
\end{array}
$$

where $\varepsilon$ is a suitably small non-negative value. In our case, the solution to the above linear optimisation model for each supplier can be obtained with negligible computing time using any public domain or professional solver. The solution yields the absolute efficiency score for each supplier, which is used for ranking suppliers in TCO-based DEA. Examining the structure of the above model, we find that the optimal solution $\left(\mathrm{U}^{\prime}, \mathrm{V}^{\prime}\right)_{\mathrm{j}_{0}}$ for a given supplier $\mathrm{j}_{0}$ is the set of weights that maximize that supplier's efficiency, provided that no other supplier in the observed set has efficiency greater than 1 with the same set of weights, as imposed by constraint (5). As a consequence, the efficiency score for $\mathrm{j}_{0}$ is the amount by which inputs should be diminished, holding output constant, to raise the efficiency to 1 . Given a set of weights $\mathrm{v}_{\mathrm{i}}$ for SPI in (1), a feasible solution $U_{1}{ }^{\prime}, V_{i}$ ' of the TCO-based DEA model in (3) can be derived. Since DEA maximizes the efficiency of a DMU with respect to the others, the TCO-based DEA efficiency score of a given DMU is not lower than the equivalent score computed starting from the TCO weights, thus introducing a certain correlation between the two rankings. This is a further evidence of the technical similarity between the SPI of TCO, and the efficiency score of TCO-based DEA. Interestingly, the most efficient DMU for TCO is ranked among the efficient units by TCO-based DEA because its normalized SPI=1 and, since DEA is not lower than normalized SPI, the TCO-based DEA efficiency score will certainly be equal to 1 .

For the "turning" category, the efficiency scores yielded by TCO-based DEA range from 0.094 to 1 , and seven suppliers are on the frontier. For the "gearwheels" category the values range from 0.007 to 1 and there are two efficient suppliers.

Compared to the TCO procedure (see Table 1), TCO-based DEA only requires a) the discussion with the department heads to analyse the internal processes involved in the supply relationship in order to identify the main cost drivers, and b) extraction of data from the ERP system. There is no need to conduct the in-depth interviews with employees to quantify the time and cost of each activity (878 hours out of a total of 959), thus reducing the total effort by $90 \%$.

\section{Research findings}

To assess the similarity of the two techniques, we first performed a correlation analysis between: (i) the SPIs obtained by TCO and the efficiency scores obtained by TCO-based DEA; and (ii) the supplier rankings generated by the two models. We computed the Pearson's correlation between the two indexes to quantify to what extent they 'go together', i.e., the degree to which the pairs of values (SPI and efficiency score) are proportional to each other. We then used two rank-based correlation measures, Spearman's rho and Kendall's tau, to quantify the agreement (in terms of order) between the two supplier rankings, taking non- 
linear and monotone association into consideration. We also controlled for potential spurious correlations arising from association between the efficiency indexes and purchased amounts (i.e., scale or volume effects). Finally, to understand whether TCO-based DEA can act as a proxy for TCO also in the most extreme cases, i.e. for the 'worst' and 'best' suppliers, we focused on the tails of the joint (bivariate) distribution to investigate whether 'large' (or 'small') values of the two efficiency indexes tend to occur together. Since the association between the two efficiency indexes might be different on the left (worst suppliers) and right (best suppliers) tails, and the correlation coefficients do not give information about the joint probabilistic behaviour of the two efficiency measures on the tails (i.e., the probability that, for a given DMU, both TCO and TCO-based DEA yield an outcome within the bounds of a given efficiency extreme), we employed the theory of copula functions (Sklar, 1959; Cherubini et al., 2004). Copulas are joint distribution functions that allow us to easily analyse the shape and strength of the association between the two efficiency indexes without any assumptions about the margins - i.e., independently of the value of the efficiency index computed by each of the two techniques - and which can account for possible asymmetric and/or non linear (non monotone) dependence patterns in the data. We focused on the two most widespread families of copula models: the Elliptical copula family and the Archimedean copula family ${ }^{1}$. Each copula model describes a different association structure and, in our case, has a single dependence parameter, $\theta$, which measures the strength of the association between the two efficiency indexes. In our analysis, a left (right) asymmetric dependence relationship between the two efficiency indexes implies that a supplier negatively (positively) evaluated by TCO is also likely to be negatively (positively) evaluated by TCO-based DEA, and vice versa. Conversely, when the association is symmetric, the dependence is stronger in the middle of the distribution than in the tails, and both tails exhibit the same behaviour, so that suppliers negatively (positively) evaluated by TCO are likely to be negatively (positively) evaluated by TCO-based DEA, and vice versa.

The above mentioned set of analyses are aimed to understand the capability of TCO to be a "good" proxy of TCO results, but they do not allow us to understand whether it is a "better" proxy than a random scoring procedure that is non-decreasing with respect to the magnitude of outputs and non-increasing with respect to the magnitude of inputs. In order to examine this aspect we also performed a Monte Carlo study where we assessed the performance of the TCO-based DEA in (3) with randomly generated weights (called, RWES, Random Weights Efficiency Score) with respect to TCO. In the next two sections, we report the results of the correlation and copula analysis obtained for the two supply categories under study, "turning" and "gearwheels". For both categories, we work with two continuous random variables in $[0 ; 1]$, since the SPI computed by TCO has been scaled to between 0 and 1 and reversed to make it comparable to the efficiency score provided by TCO-based DEA. Given the small sample size, we approximate the sampling distribution

\footnotetext{
${ }^{1}$ The Elliptical family includes the Gaussian and the Student-t copula, which are both symmetric, while the Archimedean copula family includes the symmetric Frank copula, the left asymmetric Clayton copula, and the right asymmetric Gumbel copula.
} 
of the correlation coefficients in the statistical hypothesis test using the bootstrap method (Efron and Tibshirani, 1993). In the overall analysis we perform 1000 bootstrap replications and use the bootstrap percentile method to construct confidence intervals (Efron and Tibshirani, 1993). In Appendix A we present all necessary technical details of the performed analyses and provide the mathematical proofs of the kind of weights we generate in Section 4.3. The analysis was done using the Free Software R.

\subsection{Turning category}

Table 2 reports the results of correlation analysis for the "turning" suppliers data set, while Figure 2 shows the scatter plots of the efficiency indexes obtained through TCO and TCO-based DEA in its original and ranked version. First, as for the whole data set, we note a positive and quite strong correlation between both the cardinal and ordinal values of the two efficiency indexes. The confidence intervals (CIs) are quite tight and do not contain zero, so that the null hypothesis on Spearman's $r h o, \mathrm{H}_{0}$ : rho $=0$, is rejected for all the three coefficients considered, as also confirmed by the bootstrap p-values (P-val) of the two-tailed statistical test. We also find no significant association between purchased amounts and the two efficiency indexes taken separately (for TCO-based DEA, Pearson's correlation coefficient is -0.091 with a $p$-value $=0.515$; while for TCO it is -0.125 with a $\mathrm{p}$-value $=0.376)^{2}$, so that the correlation between the two indexes being compared appears unaffected by the volume of business done with a supplier. To further verify the strong association between the efficiency indexes computed by TCO and TCO-based DEA, we performed the correlation analysis separately for suppliers with purchased amounts greater or less than the median value. Also for these two subsets of suppliers, the association between the two indexes remained quite strong, positive (Pearson's correlation coefficient $>0.81)$ and very significant $(p$-value $<=0.001)$.

Figure 2. "Turning" category: scatter plots of the original data (left panel) and its ranked version (right panel).

\footnotetext{
${ }^{2}$ These results are also confirmed by Spearman's and Kendall's correlation coefficients, but in this specific case they do not add any further information.
} 

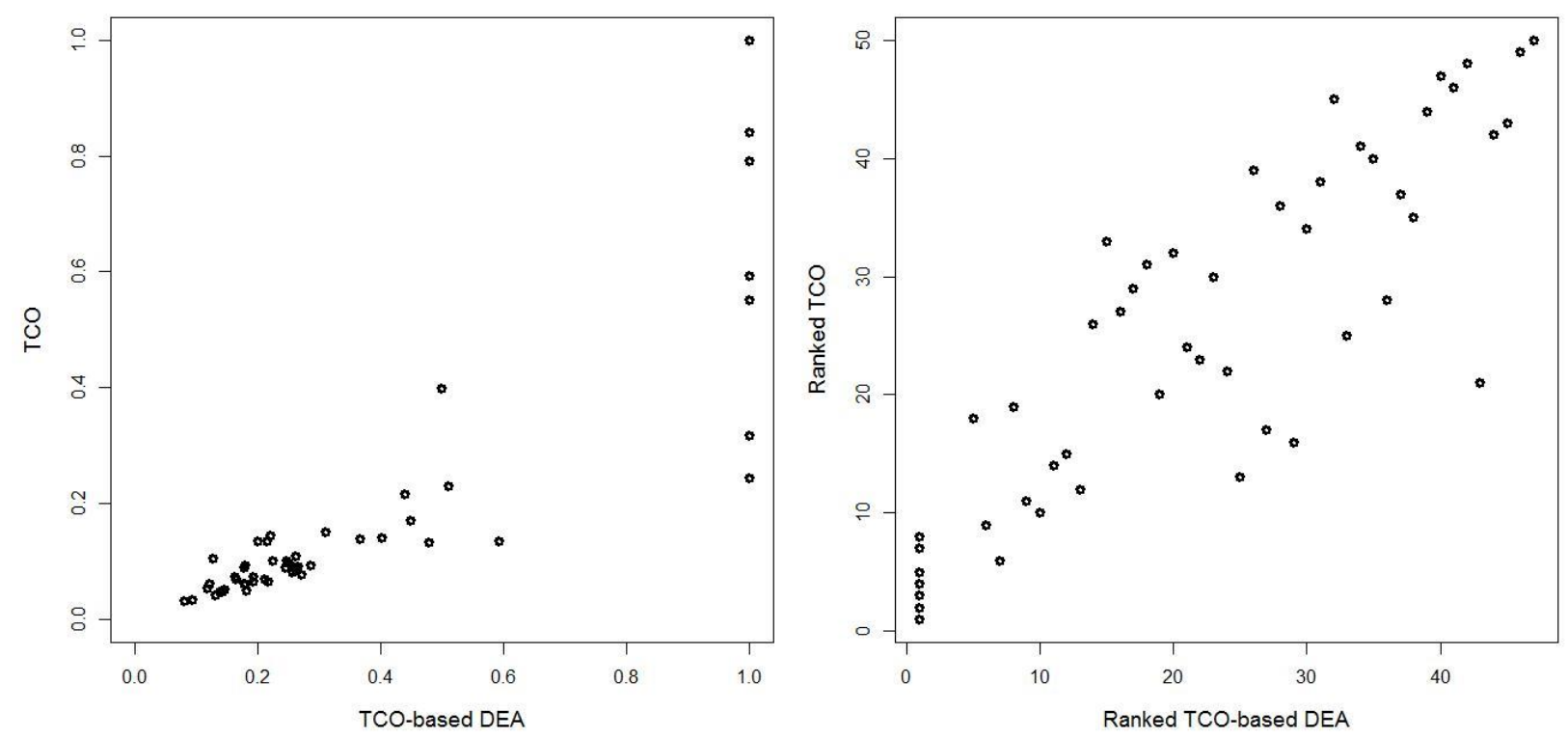

Table 2. “Turning” category: correlation analysis via bootstrap.

\begin{tabular}{l|ccccc}
\hline & rho & Bias & SD & CI & P-val \\
\hline Pearson & 0.862 & 0.005 & 0.045 & $(0.774,0.947)$ & $0.001^{* * * *}$ \\
\hline Spearman & 0.864 & -0.009 & 0.055 & $(0.723,0.938) 0.001 * * *$ \\
\hline Kendall & 0.700 & 0.001 & 0.062 & $(0.564,0.805) 0.001 * * *$ \\
\hline
\end{tabular}

$*$ p-value $<0.05 ; * *$ p-value $<0.01 ; * * *$ p-value $<0.001 ; \mathrm{NS}=$ not significant

Next, we sought to determine whether TCO and TCO-based DEA concur on the very 'small' or 'large' values of efficiency, to assess whether the latter is a valid proxy for the former also in extreme cases. In other words, given the scatter plot of the data, we wanted to assess through the copula function (Sklar, 1959; Cherubini et al. 2004) the strength and shape of the association between the observations in the upper-right and lower-left corners of the plot. We selected the Gaussian copula ${ }^{3}$ by applying the Akaike information criterion based on the value of the maximized log-likelihood copula function. Bootstrapping the dependence parameter of the selected copula model, the estimated dependence parameter $\theta$ is equal to 0.875 (with bias $=-$ 0.007 and standard deviation $\mathrm{SD}=0.036$ ) and the bootstrap percentile confidence interval is $[0.784,0.925]$. Figure 3 shows the perspective plot of the selected copula. The copula analysis confirmed that the SPI obtained by TCO is positively, strongly and symmetrically associated with the efficiency score computed by

\footnotetext{
${ }^{3}$ To estimate each copula model we employ the inference for margins estimation method (Joe and Xu, 1996) in a semiparametric fashion: the margins are estimated by the empirical cumulative distribution function and the copula through the maximum likelihood estimation method.
} 
TCO-based DEA on both tails, so that suppliers negatively evaluated ('worst' cases) by TCO are likely to also be negatively evaluated by TCO-based DEA, and vice versa. This is also true for the positively evaluated DMUs ('best' cases). Thus, TCO and TCO-based DEA appear to yield similar efficiency evaluations of a DMU.

Figure 3. "Turning” category: perspective plot of the selected Gaussian copula model with the estimated dependence parameter equal to 0.873 .

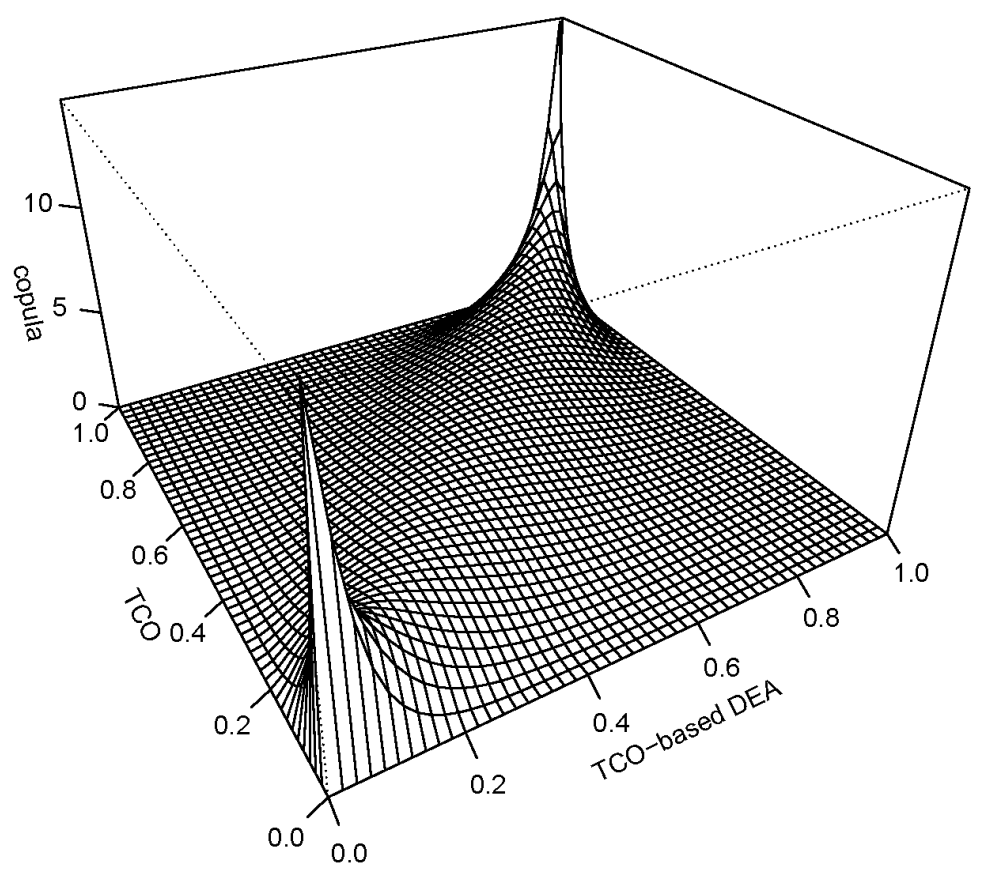

\subsection{Gearwheels category}

Table 3 and Figure 4 respectively show the results of the correlation analysis and the scatter plots of the efficiency indexes computed by TCO and TCO-based DEA for the entire data set (original and ranked version) of "gearwheels" suppliers. As for the "turning" category, there is a positive and strong correlation between both the cardinal and ordinal values of the two indexes being compared. All the confidence intervals are quite tight and do not contain zero, so that the null hypothesis $\mathrm{H}_{0}: r h o=0$ is rejected, as confirmed also by the bootstrap p-values of the statistical test. Also for this data set, the purchased amounts appear not to be significantly correlated with the efficiency index computed by either technique (Pearson's correlation coefficient equal to 0.221 with a $p$-value $=0.293$ for TCO-based DEA, and equal to 0.010 with a pvalue $=0.973$ for TCO). Moreover, the association between the efficiency indexes computed by TCO and by TCO-based DEA is still strong, positive and significant (Pearson's correlation coefficient $>0.710$ with pvalue $<=0.015$ ) for both the subset of suppliers with purchased amounts greater than the median value and the subset of suppliers with purchased amounts below the median. Hence, we can assume that the correlation 
between purchased amounts and TCO-based DEA does not affect the correlation analysis between the two efficiency indexes.

Figure 4. "Gearwheels" category: scatter plots of the original data (left panel) and its ranked version (right panel).
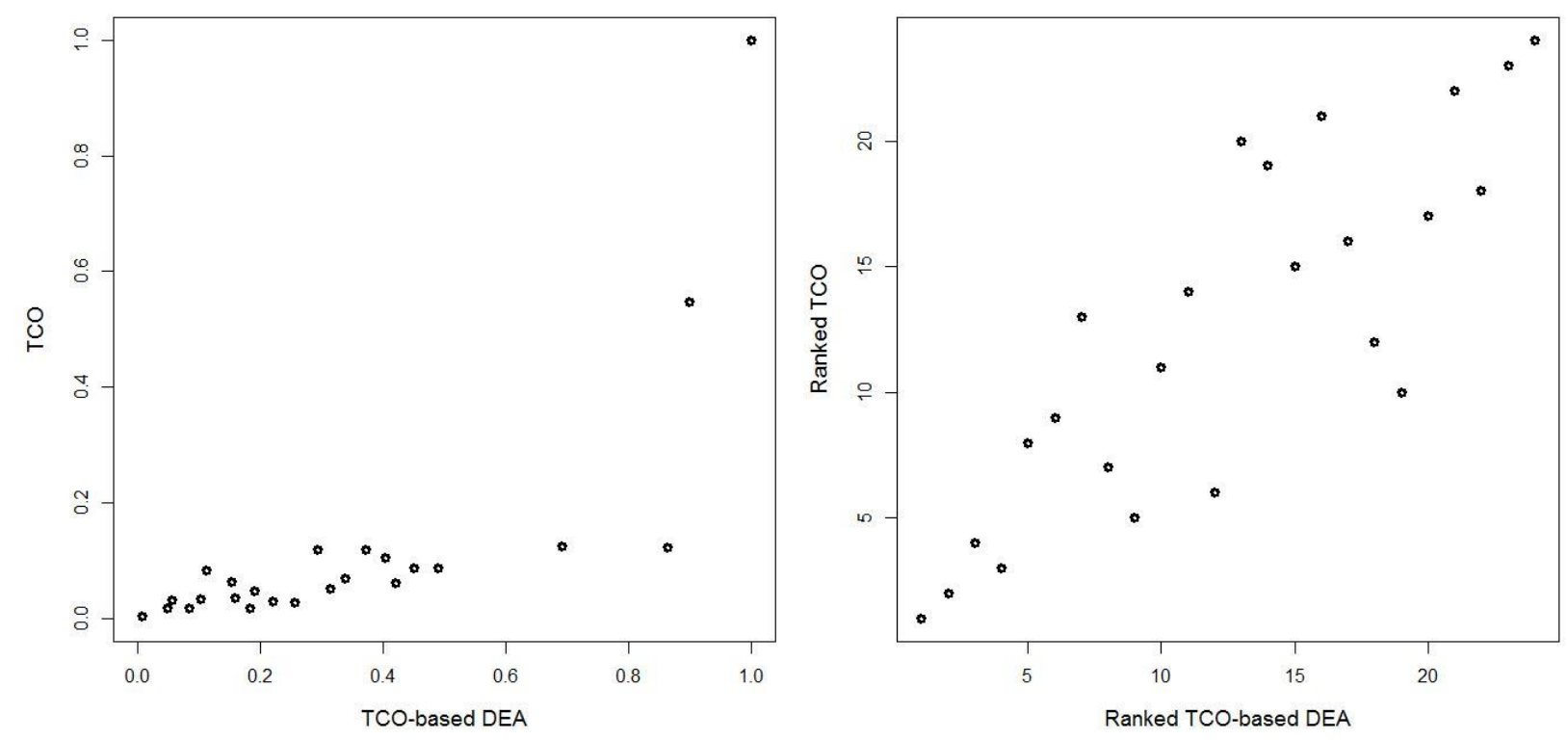

Table 3. "Gearwheels" category; correlation analysis via bootstrap.

\begin{tabular}{l|ccccc}
\hline & rho & Bias & SD & CI & P-val \\
\hline Pearson & 0.749 & 0.028 & 0.075 & $(0.635,0.912)$ & $0.001 * * *$ \\
Spearman & 0.843 & -0.015 & 0.083 & $(0.611,0.945)$ & $0.001 * * *$ \\
Kendall & 0.681 & 0.004 & 0.097 & $(0.470,0.848)$ & $0.001 * * *$ \\
\hline p-value $<0.05 ; * *$ & p-value $<0.01 ; * * *$ & p-value $<0.001$ & $\mathrm{NS}=$ not \\
significant
\end{tabular}

To investigate the extreme cases by copula function theory (Sklar, 1959; Cherubini et al., 2004) we selected the Gumbel copula model (see Figure 5). The bootstrap estimated dependence parameter $\theta$ was equal to 3.419 (with bias $=0.084$ and $\mathrm{SD}=1.325$ ) and the bootstrap percentile confidence interval was $[1.847,6.626]$. Figure 5 shows the perspective plot of the Gumbel copula, which displays a strong right-asymmetric association: the dependence relationship on the left tail of the distribution is weaker than it is on the right tail, meaning that a supplier positively evaluated by TCO is also likely to be positively evaluated by TCO-based DEA, and vice versa, whereas the association between the two efficiency indexes for negatively-evaluated suppliers is less strong. 


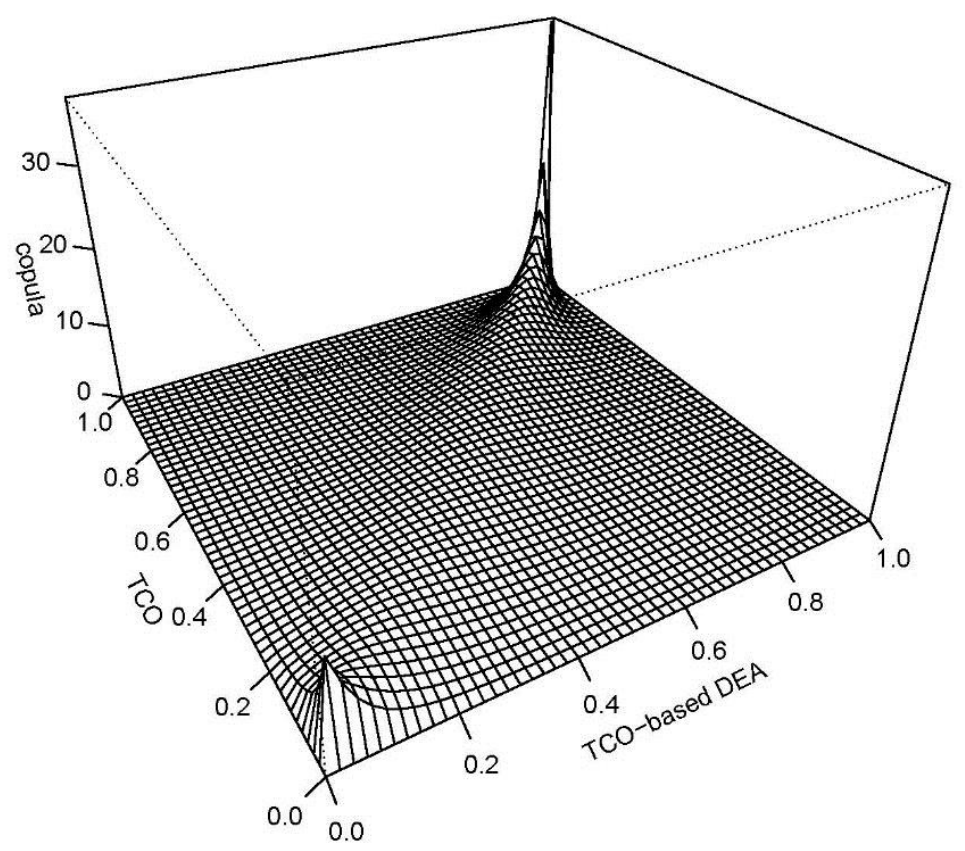

\subsection{Comparison with a random scoring procedure}

We have performed a Monte Carlo study to evaluate the performance of the RWES with respect to TCO. Therefore, we i) randomly generated non negative values as weights of the output and inputs ii) computed the resulting RWES via equation (3) and normalized it, iii) compared the RWES with the correspondent value of the TCO in terms of both cardinal and ordinal correlation (via bootstrap method). Specifically, we performed N=1000 Monte Carlo replications for each DMU and for each replication we carried out the correlation analysis based on $\mathrm{B}=1000$ bootstrap samples ${ }^{4}$. The obtained results show absence of correlation for all the three correlation coefficients employed: the coefficient rho is in the range $(-0.084,-0.126)$ with a p-value around 0.420 for the "Turning" category and it is in the range $(0.132,0.306)$ with a p-value $(0.218$, 0.453 ) for the "Gearwheels" category. Hence, the null hypothesis about the correlation coefficient is, on average, rejected and the confidence interval contains the zero value in all the investigated cases. In addition, the percentage of replications in which the null hypothesis $\mathrm{H} 0$ : $\mathrm{rho}=0$ is rejected is $0.4,7.1$ and 6.6 for the "Turning" category and 29.4, 4.1 and 5.1 for the "Gearwheels" category respectively for the Pearson's, the Spearman's and the Kendall's correlation coefficient. Hence, in at least 70\% of replications the RWES is uncorrelated with the TCO for both the categories. To conclude, the absence of correlation between TCO and

\footnotetext{
${ }^{4}$ All the details of the Monte Carlo study are reported in Appendix A.
} 
a ranking based on randomly generated normalized weights and the strong correlation between TCO-based DEA and TCO are evidence of the potentiality of the TCO-based DEA as a proxy of TCO.

\section{Discussion and managerial implications}

The objective of this study was to empirically explore the effectiveness of TCO-based DEA in approximating supplier TCO. As discussed in the literature section, notwithstanding its potential benefits, the complex and time-consuming data collection process of TCO is a major barrier to its adoption. A reliable, parsimonious 'proxy' for TCO would enable firms to evaluate and compare suppliers without incurring the substantial investments in time and costs of directly implementing TCO.

Our analysis, performed on two main supply categories of a leading power transmissions equipment firm, suggests that TCO-based DEA may be able to effectively approximate the efficiency measure provided by TCO (the SPI). We found a strong, positive, and statistically significant correlation between both the absolute efficiency indexes (i.e., the cardinal values) and the rankings (i.e., the ordinal values) generated by the two techniques. Our proposed proxy also proved quite effective on the tails of the two samples, meaning it is able to clearly detect the best and worst performers. For example, among the turning suppliers, TCObased DEA correctly identified $83.3 \%$ (10 out 12 ) of the suppliers in the upper tail of the TCO ranking (i.e., the top $25 \%$ ), and it exactly reproduced $87.5 \%$ ( 7 out of 8 ) of the top eight positions in the TCO efficiency rankings. TCO-based DEA also did not greatly underestimate the relative performance of the two suppliers which it 'excluded' from the upper $25 \%$ (i.e. from the top 12), ranking them $13^{\text {th }}$ and $16^{\text {th }}$ respectively. Similarly, the two suppliers which TCO-based DEA did include among the upper 25\% (but which TCO did not) were anyway above the median in the TCO ranking, suggesting that overestimation was likewise relatively low.

We obtained similar results for the lower tail (i.e. for the poorest performers) of turning suppliers, and for both tails of the gearwheel suppliers. Overall, there was only one instance where TCO-based DEA and TCO did not assign a supplier to the same or to adjoining quartiles of the ranking. The effectiveness of TCO-based DEA in approximating TCO appeared unaffected by the volume of business with the suppliers, and held for both of the sourcing categories considered in our analysis. This is interesting because, owing to differences in technological features, market characteristics, and supply relationships, the purchasing process for turning and gearwheels is managed differently. Yet, despite these differences, for both turning and gearwheels the efficiency indexes and rankings provided by TCO-based DEA resemble those obtained by TCO. TCO-based DEA thus seems to remain able to approximate TCO under a variety of sourcing conditions. Finally, the Monte Carlo study demonstrates that the strong correlation with TCO cannot be obtained by a generic efficiency measure generated by randomly weighting the same inputs and outputs.

In light of these encouraging empirical findings, we attempted to figure out which theoretical motivations could explain them. Due to the different procedures for weighting inputs and outputs, TCO and TCO-based DEA scores can theoretically diverge. Specifically, this can occur whether the inputs of TCO drive quite different amounts of costs and the efficiency of the suppliers on the "less relevant" cost drivers (the ones 
driving a little amount of costs) is significantly different from that on the "more relevant" ones. This situation is theoretically possible and it may always happen in artificial experiments. However, we contend that from a managerial point of view, in practice it has limited impact on the effectiveness of TCO-based DEA in approximating the results of TCO, because it is either relatively uncommon, and manageable by experienced executives.

First, practices that typically characterize an effective operations strategy, such as total quality management and integrated supply chain management, have been found to positively impact several dimensions of operational performance (e.g., Samson and Terziovski, 1999; Merino-Diaz de Cerio, 2003; Kannan and Tan, 2005), thus reducing the probability that drastic asymmetries will occur between efficiency on different cost drivers of the same DMU.

Second, in case that - for some contingent reasons (e.g., specialization on a specific capability) - one DMU should score heavily only on a cost driver that drives little or negligible amount of costs (i.e., be DEAefficient but not TCO-efficient), procedures for identifying the "truly good performing DMUs" can be applied (Talluri et al., 2013), by analyzing the scores obtained by efficient DMUs on each input.

Third, experienced executives can proactively reduce these kinds of distortions by not including irrelevant cost drivers in the set of inputs they consider for the TCO-based DEA. Clearly, while performing TCO-based DEA, the exact amount of costs driven by each input/cost driver is unknown since the timesaving obtained through TCO-based DEA derives precisely from removing the cost analysis procedure. In any case, in a first approximation, the amount of costs driven by each input/cost driver can be estimated and thus only the most relevant cost drivers can be selected.

To the best of our knowledge, this is the first attempt to propose and empirically test a tool that can act as a parsimonious, easy-to-apply 'proxy' for TCO. Although further investigation is needed to validate the effectiveness and reliability of TCO-based DEA, it has apparent potential managerial implications. We can examine these through the lens of Ellram's framework (1994) for the applications of TCO to sourcing decisions, presented in Section 2.1.

First, TCO-based DEA can be used for internal purposes, to help measure and compare the ongoing performance of suppliers over time. Since TCO-based DEA is simple to implement and relies on information (e.g. orders, quality warnings, delays) that is generally available both on modern ERP systems and more conventional IT systems, it allows firms to continually monitor their suppliers' efficiency (Visani et al., 2012). This is useful because it can help detect declining supplier performance and facilitate timely remedial actions. Thus, its simplicity overcomes the main barriers to implementing TCO: the unavailability of data for performing total cost analysis (Ellram and Siferd, 1998; Hurkens et al., 2006) and the inherent complexity of the calculation process. Especially where the number of suppliers is high--so that one-to-one performance comparisons among them would be expensive--this tool enables firms to rapidly rank the performance of their suppliers based on a valid efficiency index that is comparable to TCO.

A second major potential application of TCO-based DEA is in supporting strategic processes for rationalising and reducing the supplier base. The tool showed high effectiveness in approximating TCO on 
the upper and lower tails of the distribution, i.e., in detecting the best and worst suppliers. Particularly where suppliers are essentially interchangeable, this is a sound criterion for deciding which relationships should be strengthened (i.e., those with suppliers on the upper tail of the distribution), and which ones are expendable (i.e., those with suppliers on the lower tail). TCO-based DEA enables companies to apply this criterion without having to directly implement an expensive activity-based costing approach (Degraeve and Roodhooft, 1999). Also, TCO-based DEA requires less commitment from other departments affected by purchasing decisions (Wouters et al., 2005), thereby contributing to quicker decision-making.

The tool can also demonstrate usefulness in more complex cases, where suppliers are less interchangeable. Since supplier selection (and/or allocation of business among suppliers) in such situations depends more on their technological expertise and 'soft factors' not captured by TCO, companies can combine TCO-based DEA with other relevant considerations to improve their sourcing decisions. The case of company Alpha illustrates this point well, particularly for turning suppliers. As Alpha's CPO explained, "Allocation of business to suppliers is our most important task today. We first of all need some suitable criteria to compare suppliers ' performance and target the suppliers we would prefer to keep, but that is just the starting point for us. While in principle we know "who can do what", a precise assessment of a supplier's capability to replace another one is indeed complex. Besides, it is not just a matter of the suppliers' technical competencies. By providing a way to compare suppliers' efficiency with only a limited effort, TCO-based DEA could enable purchasing executives to rapidly carry out the first step of the business consolidationsupply base reduction process and then better focus on the remaining ones".

Third, TCO-based DEA may be effective in assisting the negotiation process. The mathematical measure of relative efficiency which it provides may be perceived as more objective and transparent by suppliers involved in a negotiation. TCO-based DEA information is also easier than to share for negotiation purposes, since it only requires explaining the drivers used to compare efficiency, rather than the complex calculation process that leads to quantifying TCO. The existing literature suggests that trust and transparency of cost structures are key success factors in fostering collaborative efforts for the reduction of supply-chain costs (Kajüter and Kulmala, 2005).

The ability of TCO-based DEA to approximate TCO and to support similar decisions does not mean that the two approaches are identical and completely interchangeable. We suggest that the choice of method should be contingent on the nature of the purchasing decision. A comprehensive analysis of the resources absorbed by the purchasing process and the calculation of the actual cost of dealing with different suppliers can only be accomplished by fully-fledged TCO. That said, for selection or allocation decisions, TCO-based DEA may be a better option due to its simplicity and ability to be combined with 'soft' dimensions of supplier evaluation. The size of a company and its industry may also tip the balance in favour of one or the other method, even when the two are interchangeable. For instance, medium-sized companies may favour the TCO-based DEA approach owing to the stronger resource constraints they face, and industries where transparency issues are especially relevant (e.g. public administrations) may benefit from introducing TCObased DEA for supplier selection. 


\section{Limitations and future developments}

We conclude with remarks on the limitations of our study and suggestions for future developments. A first limitation to consider when drawing conclusions from this work is that it is based on a single purchasing company. Although the results are consistent for the two sourcing categories, care should be taken in generalizing its outcomes.

Second, we think that this study should be followed up by further empirical work investigating the reliability of TCO-based DEA in approximating TCO under various conditions. Two particularly stand out. (1) The role of domination relationships among suppliers. The existence of "dominating suppliers" (i.e., suppliers more efficient than others on all the cost drivers) increases the correlation (as well as the statistical significance) between the results of the two techniques, i.e., contributes to the acceptance of the results based on statistical considerations. However, a "good" proxy can be considered effective and useful if able to recognize the right efficiency order between two distinct suppliers when the more efficient one does not outperform the less efficient one on all the cost drivers. While in our case TCO-based DEA usually proved effective in doing this, further investigation on the impact of dominating suppliers is recommended. (2) The fact that SPI is computed on a common set of weights while TCO-based is not, could result in a situation of "inherent inconsistency" where the ranking obtained by TCO-based DEA cannot be obtained by any common weights. A situation such as this could occur for instance when there is high supplier performance variability on the "more relevant" and "less relevant" cost drivers. As discussed in the previous section, such situations of dissimilarity between the two efficiency indexes are theoretically possible, but in terms of managerial considerations we expect these to be relatively uncommon and their impact on the proxy's effectiveness identifiable and manageable. Nevertheless, the actual occurrence and impact of this phenomenon requires further study.

Third, our study was aimed at identifying a "parsimonious" and easily applicable proxy of the TCO results and not at improving the TCO methodology itself. As such, TCO-based DEA presents some of the issues that normally characterize TCO. Two main aspects are particularly worth considering: (1) the inclusion of qualitative criteria to complete the supplier's evaluation; (2) the extension of the analysis to new, unknown suppliers. Inherent difficulties exist in the cost evaluation of "quasi-quantitative" (e.g., personal costs, past experience) and soft factors that characterize the buyer-supplier relationships (Ellram, 1995) while TCO is better suited to those situations where cost is a high priority and detailed cost data are available to make comparisons (Bhutta and Huq, 2002). In its current form, TCO-based DEA also disregards qualitative factors. Extensions of the TCO-based DEA model that could at least partially remedy this limitation may prove useful as they would maintain parsimony in the estimation of the cost factors while accounting for soft, albeit relevant, factors. Literature offers some starting points on how these extensions could be built. For example, Kumar et al. (2011) combine total cost of ownership with more qualitative supplier selection criteria and assign weights to each criterion to create a supplier selection matrix. This tool is used to determine which supplier to enter into a long-term supply relationship with. TCO-based DEA could be used 
instead of fully-fledged TCO in this matrix. Ramanathan (2007) suggests that DEA can be advantageously employed to integrate objective (namely, TCO) and subjective (namely, Analytical Hierarchy Process, AHP) methods for supplier evaluation. Building on Bhutta and Huq's study (2002), he develops a DEA model that uses total cost as input and AHP weighted scores in terms of quality, technology and service as outputs to determine the most efficient supplier(s). Again, our TCO-based DEA could be used in this tool as a replacement for total cost. The tool would become a "two-step DEA" as it would use DEA twice: first, to approximate the supplier's total cost value and then to examine supplier efficiency in transforming costs (i.e., the input) into quality, technology and service performance (i.e., the output).

Fourth, the TCO methodology, and consequently our TCO-based DEA, are only applicable to those suppliers that already work (or have worked) with the company. Data normally used as cost drivers cannot be gathered for unknown suppliers. As a partial response to this issue, a statistical analysis of actual suppliers could be performed to identify the main factors affecting their TCO performance (e.g., industry, size, geographic localization, availability of specific technologies, adoption of specific production techniques such as lean management or total quality management, etc.). This would represent a basis to develop a set of predictors to estimate the performance of new suppliers. Future research could then investigate how to obtain these predictors and their use in the TCO-based DEA.

Fifth, future studies could help the understanding of the types of decisions and contexts that would particularly benefit from TCO-based DEA. For instance, a dynamic DEA model (Färe et al., 1994; Tone and Tsutsui, 2010) could be applied to measure efficiency change over time and to understand the capability of TCO-based DEA to approximate the suppliers' TCO evolution.

Finally, we focus on only the "technical" aspects of TCO-based DEA (i.e., its ability to provide a proxy of TCO scores and more effortless ranking) disregarding its potential to reduce the ambiguity of the results (Vakkury and Meklin, 2006). The effectiveness of TCO analysis is indeed often restricted by the cognitive limitations of users (buyers and purchasing officers without a financial education) who do not fully understand the source of the values and the meaning of the results or misrepresent the potential effect of managerial actions on total cost. Future analyses on TCO-based DEA could be directed at understanding the impact on these issues.

\section{Appendix A Monte Carlo study via boostrap: technical details}

In this section, we describe the procedure employed to perform Monte Carlo studies via bootstrap method (Efron and Tibshirani, 1993) which have been carried out in the paper. In Section A1.1, we explain in details the procedure for a generic correlation coefficient $r h o$ and for the dependence parameter $\theta$ of a copula model. As for the Monte Carlo study performed in Section 4.3 of the paper, we provide the mathematical proof of the kind of weights used for inputs and outputs of the Random Weights Efficiency Score (RWES) and we specify some computational information to make the simulation reproducible.

\section{A1.1 Bootstrap-based procedure to estimate correlation coefficients and copula parameter}


Here we describe the bootstrap-based estimation of a generic correlation coefficient rho with its bias, standard error, confidence interval, and the p-value concerning the statistical test about $\mathrm{H}_{0}: r h o=0$. In this context, the bootstrap-based approach is fully nonparametric (Martinez and Martinez, 2002) so that the distribution underlying the data does not have to be known or assumed. The steps of the procedure are described in the following.

Given a bivariate data set of size $n$, say $\left(\mathrm{x}_{1}, \mathrm{y}_{1}\right),\left(\mathrm{x}_{2}, \mathrm{y}_{2}\right), \ldots,\left(\mathrm{x}_{\mathrm{n}}, \mathrm{y}_{\mathrm{n}}\right)$, the population parameter rho (e.g. Pearson's, Kendall's or Spearman's correlation coefficient) is estimated by $r \widehat{h} o$. Resampling is then done with replacement from the original data set to obtain a bootstrap bivariate sample of size $n$, say $\left(\mathrm{x}_{1}{ }^{{ }^{\mathrm{b}}}, \mathrm{y}_{1}{ }^{* \mathrm{~b}}\right)$, $\left(\mathrm{x}_{2}{ }^{* b}, \mathrm{y}_{2}{ }^{* b}\right), \ldots,\left(\mathrm{x}_{\mathrm{n}}{ }^{* \mathrm{~b}}, \mathrm{y}_{\mathrm{n}}{ }^{*}\right)$, where $b$ represents the $\mathrm{b}$-th bootstrap sample, and the same statistic as above is computed obtaining $r \widehat{h} o^{* b}$. In order to break the original pairing in the data, resampling with replacement is done by resampling $\mathrm{X}$ and $\mathrm{Y}$ independently, with resamples then allocated to pairs. Resampling is performed $B=1000$ times in order to take into account the source of variability deriving from the randomness of the mechanism of generation of bootstrap samples, so that 1000 estimates of the parameter of interest are obtained. The empirical bootstrap distribution of $r \widehat{h} o^{*}$ is then defined and used to compute the bootstrap estimation of $r h o$ and all the statistical quantities of interest. In particular, we compute

1. the bootstrap estimation of the correlation coefficient with its bias and standard error respectively by

$$
\begin{gathered}
r \widehat{h} o^{*}=\sum_{b=1}^{B} \frac{\widehat{r h} o^{* b}}{B-1} \\
\operatorname{Bias}\left(\widehat{r h o^{*}}\right)=r \widehat{h} o^{*}-r \widehat{h o} \\
S E(\widehat{r h o})=\sqrt{\sum_{b=1}^{B} \frac{\left(\widehat{r h o} o^{* b}-r \widehat{h} o^{*}\right)^{2}}{B-1}}
\end{gathered}
$$

2. the bootstrap percentile confidence interval for a correlation coefficient by

$$
C I_{r \widehat{h o}}=\left[r \widehat{h} o^{*}\left(\frac{\alpha}{2}\right), \widehat{r h o} *\left(1-\frac{\alpha}{2}\right)\right]
$$

where $r \widehat{h}^{*}\left(\frac{\alpha}{2}\right)$ and $r \widehat{h}^{*\left(1-\frac{\alpha}{2}\right)}$ are, respectively, the $\frac{\alpha}{2}$ and $\left(1-\frac{\alpha}{2}\right)$-quantiles of the bootstrap distribution of estimates $\widehat{r h o}^{*}$; note that the bootstrap percentile confidence interval works better for the correlation coefficient than a $t$-like test statistic because of the difficulty in forming a reliable variance estimator for the sample correlation coefficient (Hall, 1988);

3. the bootstrap p-value $p_{\widehat{r h o}}$ for a two-sided statistical test about $\mathrm{H}_{0}: r h o=0$ by

$$
p_{r \widehat{h o}}=\frac{1}{B} \sum_{b=1}^{B} \mathrm{I}\left(\left|r \widehat{h} o^{* b}\right|>|r \widehat{h} o|\right)
$$


that is, by the fraction of the bootstrap samples for which $\left|r \widehat{h o} o^{* b}\right|$ is greater than $|r \widehat{h o}|$.

As for the dependence parameter $\theta$ of (any) copula model used along the paper, we employed the nonparametric bootstrap sampling method for parametric inference (Meeker and Escobar, 1998). Similar to the fully nonparametric method, the nonparametric bootstrap for parametric inference method samples with replacement from the original bivariate data $\left(\mathrm{x}_{1}, \mathrm{y}_{1}\right),\left(\mathrm{x}_{2}, \mathrm{y}_{2}\right), \ldots,\left(\mathrm{x}_{\mathrm{n}}, \mathrm{y}_{\mathrm{n}}\right)$, but for each bootstrap sample of size $n$, maximum likelihood estimates are realized from the specific parametric copula model. To estimate $\theta$, we first estimate marginal distributions by the empirical cumulative distribution function (multiplied by $n /(n+1)$ to avoid problems at the boundary $\left.[0,1]^{2}\right)$ and, then, the copula parameter through the maximum likelihood estimation method. These maximum likelihood estimates are then used to estimate the population parameter $\theta$ and form the bootstrap distribution of $\hat{\theta}^{*}$. The bootstrap estimation of the dependence parameter $\widehat{\theta}^{*}$ with its standard error $S E\left(\widehat{\theta}^{*}\right)$, bias $\operatorname{Bias}\left(\widehat{\theta}^{*}\right)$, percentile confidence interval $C I_{\widehat{\theta}^{*}}$ and $\mathrm{p}$-value $p_{\widehat{\theta}^{*}}$ are computed as above described.

In order to make reproducible the performed analysis the seed of the bootstrap sampling has been set to 11 for the "Turning" category and to 14 for the "Gearwheels" category.

\section{A1.2 Generation of weights of the output and inputs}

To evaluate the performance of the RWES with respect to TCO, we performed a Monte Carlo study where we randomly generated non-negative values as weights of the output and inputs; next, we computed the resulting RWES via equation (3) in the paper and normalized it. The comparison between the RWES with the correspondent value of the TCO in terms of both cardinal and ordinal correlation has been performed via bootstrap method. Specifically, we performed $N=1000$ Monte Carlo replications for each DMU and for each replication we carried out the correlation analysis based on $B=1000$ bootstrap samples following the lines described in Section A1.1.

Now we provide the mathematical proof of the kind of weights we generated.

Definition. We say that a function $f\left(x_{1}, \ldots, x_{m}, y\right): \mathbb{R}_{+}^{*, m} \times \mathbb{R}_{+} \rightarrow \mathbb{R}$, where $\mathbb{R}_{+}^{*, m}=\mathbb{R}_{+}^{m} \backslash\{(0, \ldots, 0)\}$, is a weighting function for a DMU that takes $m$ inputs $x_{1}, \ldots, x_{m}$ and produces one output $y$, if:

1. $f$ increases as the output increases:

$$
f\left(x_{1}, \ldots, x_{m}, y+\Delta y\right) \geq f\left(x_{1}, \ldots, x_{m}, y\right) \quad \forall \Delta y \geq 0
$$

2. $f$ decreases as any of the inputs increases:

$$
f\left(x_{1}, \ldots x_{i}+\Delta x_{i}, \ldots, x_{m}, y\right) \leq f\left(x_{1}, \ldots, x_{i}, \ldots x_{m}, y\right) \quad \forall \Delta x_{i} \geq 0, i=1, \ldots, m
$$

In particular, we consider weighting functions defined as the weighted ratio between output and inputs with 
weights $u_{1}$ and $v_{1}, \ldots, v_{m}$, respectively and expressed as

$f_{u, v}\left(x_{1}, \ldots, x_{m}, y\right)=\frac{u_{1} y}{v_{1} x_{1}+\cdots+v_{m} x_{m}}$

The choice of the weights such that (1) is a weighting function is determined by the following:

Theorem. If weights $u_{1}$ and $v_{1}, \ldots, v_{m}$ have all the same sign, and $v_{1}, \ldots, v_{m}$ are not all equal to zero, then the weighted ratio (1) is a weighting function.

Proof. Let us consider the first condition of the weighting function definition, i.e., that the function is increasing as the output increases. This condition clearly holds if the partial derivative of the weighting ratio (1) with respect to the output is non-negative. More precisely,

$$
\frac{\partial}{\partial y} f_{u, v}\left(x_{1}, \ldots, x_{m}, y\right)=\frac{u_{1}}{v_{1} x_{1}+\cdots+v_{m} x_{m}} \geq 0
$$

Since, by definition, $x_{i} \geq 0 \forall i$, the partial derivative is non-negative if and only if the weights have all the same sign and the $v_{1}, \ldots, v_{m}$ are not all zero.

With similar arguments we can address the second condition that requires the weighting function to decrease as any of the inputs increases. To this end we should consider the partial derivatives of (1) with respect to each input and impose they are non-positive. The partial derivative with respect to a generic input $x_{i}$ is

$$
\frac{\partial}{\partial x_{i}} f_{u, v}\left(x_{1}, \ldots, x_{m}, y\right)=u_{1} y \frac{-v_{i}}{\left(v_{1} x_{1}+\cdots+v_{m} x_{m}\right)^{2}}
$$

This expression is non-positive whenever $-u_{1} y v_{i} \leq 0$. Because $y \geq 0$, this is verified if and only if the weights have all the same sign. Moreover, the $v_{1}, \ldots, v_{m}$ must not be all zero.

Because weights $u_{1}, v_{1}, \ldots, v_{m}$, which are feasible solutions of the TCO-based DEA, are all non-negative, an 
immediate consequence of the Theorem is that the TCO-based DEA objective function for a generic DMU computed with respect to the optimal weights is actually a weighting function. Hence, we can compare the performance optimal values of the weights computed with the TCO-based DEA with other weighting functions.

\section{References}

Al-Alawi, B.M., and Bradley, T.H. (2013), "Total cost of ownership, payback, and consumer preference modeling of plug-in hybrid electric vehicles", Applied Energy, Vol. 103, pp. 488-506.

Banker, R., Charnes, A. and Cooper, W. (1984), "Some models for estimating technical and scale inefficiencies in Data Envelopment Analysis”, Management Science, Vol. 30, No 9, pp. 1078-1092.

Bhutta, K.S., and Huq, F. (2002), "Supplier selection problem: a comparison of the total cost of ownership and analytic hierarchy process approaches", Supply Chain Management: An International Journal, Vol. 7, No. 3, pp. 126-135.

Bhutta, M.K.S. (2003), "Supplier selection problem: Methodology literature review", Journal of International Technology and Information Management, Vol. 12, No. 2, pp. 53-71.

Caniato, F., Ronchi, S., Luzzini, D., and Brivio, O. (2014), "Total cost of ownership along the supply chain: a model applied to the tinting industry", Production Planning \& Control, (forthcoming).

Carr, A.S. and Pearson, J.N. (1999), "Strategically managed buyer-seller relationships and performance outcomes", Journal of Operations Management, Vol. 17, No. 5, pp. 497-519.

Carr, L.P., and Ittner, C.D. (1992), "Measuring the cost of ownership", Journal of Cost Management, Vol. 6, No. 3, pp. $42-51$.

Cavinato, J.L. (1991), "Identifying interfirm total cost advantages for supply chain competitiveness", International Journal of Purchasing and Materials Management, Vol. 27, No. 4, pp. 1015.

Charnes A., Cooper W.W., Lewin A.Y., and Seiford L.M. (Eds) (1994), Data envelopment analysis: theory, methodology and application, Kluwer Academic Publisher, Norwell, MA.

Charnes, A., Cooper, W.W., and Rhodes, E. (1978), "Measuring the efficiency of decision making units", European Journal of Operational Research, Vol. 2, No. 6, pp. 429-444.

Cherubini, U., Luciano, E., and Vecchiato, W. (2004), Copula Methods in Finance, Wiley Finance Series, Chichester: John Wiley \& Sons Ltd.

Cooper, W.W., Seiford, L.M., and Kaoru, T. (2007), Data Envelopment Analysis, Springer. 
Danese, P. (2013), "Supplier integration and company performance: A configurational view", Omega, Vol. 41, pp. 1029-1041.

de Boer, L., Labro, E., and Morlacchi, P. (2001), "A review of methods supporting supplier selection", European Journal of Purchasing and Supply Management, Vol. 7, No. 2, pp. 75-89.

Degraeve, Z., and Roodhooft, F. (1999), "Improving the efficiency of the purchasing process using total cost of ownership information: The case of heating electrodes at Cockerill Sambre SA", European Journal of Operational Research, Vol. 112, No. 1, pp. 42-53.

Degraeve, Z., and Roodhooft, F. (2000), "A mathematical programming approach for procurement using activity based costing", Journal of Business Finance \& Accounting, Vol. 27, No. 1-2, pp. 69-98.

Degraeve, Z., Labro, E., and Roodhooft, F. (2000), “An evaluation of vendor selection models from a total cost of ownership perspective", European Journal of Operational Research, Vol. 125, No. 1, pp. 34-58.

Degraeve, Z., Roodhooft, F., and Van Doveren, B. (2005), “The use of total cost of ownership for strategic procurement: a company-wide management information system”, Journal of the Operational Research Society, Vol. 56, No. 1, pp. 51-59.

Ding, J., Dong, W., Bi, G. and Liang, L. (2015), “A decision model for supplier selection in the presence of dual-role factors", Journal of the Operational Research Society, Vol. 66, No. 5, pp. 737-746.

Efron, B. and Tibshirani, R. (1993). An Introduction to the Bootstrap. Chapman \& Hall/CRC, Boca Raton, FL.

Ellram, L. (1994), “A taxonomy of total cost of ownership models”, Journal of Business Logistics, Vol. 15, pp. 171-191.

Ellram, L.M. (1995a), “Total cost of ownership: an analysis approach for purchasing”, International Journal of Physical Distribution \& Logistics Management, Vol. 25, No. 8, pp. 4-23.

Ellram, L.M. (1995b), “Activity-based costing and total cost of ownership: a critical linkage", Journal of Cost Management, Vol. 8, No. 4, pp. 22-30.

Ellram, L.M., and Siferd, S.P. (1998), "Total cost of ownership: a key concept in strategic cost management decisions", Journal of Business Logistics, Vol. 19, pp. 55-84.

Färe, R., Grosskopf, S., Norris, M., and Zhang, Z. (1994), "Productivity growth, technical progress, and efficiency change in industrialized countries", The American Economic Review, Vol. 84, No. 1, pp. 66-83.

Ferrin, B.G., and Plank, R.E. (2002), “Total cost of ownership models: an exploratory study”, Journal of Supply Chain Management, Vol. 38, No.3, pp. 18-29. 
Garfamy, R.M. (2006), “A data envelopment analysis approach based on total cost of ownership for supplier selection", Journal of Enterprise Information Management, Vol. 19, No. 6, pp. 662-678.

Hall, P. (1988). "Theoretical comparison of bootstrap confidence intervals (with discussion)". Ann. Statist. $16,927-953$.

Ho, W., Xu, X. and Dey, P.K. (2010), "Multi-criteria decision making approaches for supplier evaluation and selection: A literature review", European Journal of Operational Research, Vol. 202, No. 1, pp. 16-24.

Ho, W., Dey, P.K. and Lockstrom, M. (2011), "Strategic sourcing: a combined QFD and AHP approach in manufacturing", Supply Chain Management: An International Journal, Vol. 16, No. 6, pp. 446-61.

Hopkins M. (2010), "Your Next Supply Chain”, MIT Sloan Management Review, Vol. 51, No. 2, pp. 17-24.

Hurkens, K., Valk, W., and Wynstra, F. (2006), "Total cost of ownership in the services sector: a case study", Journal of Supply Chain Management, Vol. 42, No. 1, pp. 27-37.

Jackson, D.W., and Ostrom, L.L. (1980), "Life cycle costing in industrial purchasing", Journal of Purchasing and Materials Management, Vol. 16, No. 1, pp. 8-12.

Jain, V., Benyoucef, L., and Deshmukh, S.G. (2009), "Strategic supplier selection: some emerging issues and challenges", International Journal of Logistics Systems and Management, Vol. 5, No. 1/2, pp. 61-88.

Joe, H., and Xu, J. (1996), The Estimation Method of Inference Functions for Margins for Multivariate Models, Technical Report, University of British Columbia, Department of Statistics.

Kajüter, P., and Kulmala, H.I. (2005), “Open-book accounting in networks: Potential achievements and reasons for failures", Management Accounting Research, Vol. 16, No. 2, pp. 179-204.

Kanagaraj, G., and Jawahar, N. (2009), "A simulated annealing algorithm for optimal supplier selection using the reliability-based total cost of ownership model", International Journal of Procurement Management, Vol. 2, No. 3, pp. 244-266.

Kannan, V.R., and Tan, K.C. (2005), "Just in time, total quality management, and supply chain management: understanding their linkages and impact on business performance", Omega, Vol. 33, pp. 153-162.

Kasperskaya, Y., and Tayles, M. (2013), "The role of causal links in performance measurement models", Managerial Auditing Journal, Vol. 28, No. 5, pp. 426-443.

Kumar, S., Hong, Q.S., and Haggerty, L.N. (2011), “A global supplier selection process for food packaging”, Journal of Manufacturing Technology and Management, Vol. 22, No. 2, pp. 241-260.

Kumar, A., Jain, V. and Kumar, S. (2014), “A comprehensive environment friendly approach for supplier selection", Omega, Vol. 42, pp. 109-123. 
Lawson, B., Cousins, P.D., Handfield, R.B., and Petersen, K.J. (2009), "Strategic purchasing, supply management practices and buyer performance improvement: an empirical study of UK manufacturing organizations", International Journal of Production Research, Vol. 47, No. 10, pp. 2649-2667.

Liker, J.K., and Choi, T.Y. (2004), "Building deep supplier relationships", Harvard Business Review, Vol. 82, No. 12, pp. 104-112.

Liu, J., Ding, F.Y., and Lall, V. (2000), "Using data envelopment analysis to compare suppliers for supplier selection and performance improvement", Supply Chain Management: An International Journal, Vol. 5, No. 3, pp. 143-150.

Liu, J.S., Lu, L.Y., Lu, W.M., and Lin, B.J. (2013a), “A survey of DEA applications”, Omega, Vol. 41, No. 5, pp. 893-902.

Liu, J.S., Lu, L.Y., Lu, W.M., and Lin, B. J. (2013b), "Data envelopment analysis 1978-2010: A citationbased literature survey", Omega, Vol. 41, No. 1, pp. 3-15.

Liu, J.S., Lu, L.Y. and Lu, W.M. (forthcoming), "Research Fronts in data envelopment analysis", Omega, DOI: http://dx.doi.org/10.1016/j.omega.2015.04.004.

March J.G., and Sutton, R.I. (1997), “Organizational Performance as a Dependent Variable”, Organization Science, Vol. 8, No. 6, pp. 698-706.

Martinez, W.L. and Martinez, A.R. (2002). Computational Statistics Handbook with Matlab. Chapman and Hall/CRC, Boca Raton, Louisiana.

Meeker, W.Q. and Escobar, L.A. (1998). Statistical Methods for Reliability Data. Wiley, New York.

Merino-Diaz de Cerrio, J. (2003), "Quality management practices and operational performance: empirical evidence for Spanish industry”, International Journal of Production Research, Vol. 41, No. 12, pp. 27632786.

Milligan, B. (1999), “Tracking total cost of ownership proves elusive”, Purchasing, Vol. 127, No. 3, pp. 2223.

Minner, S. (2003), "Multiple-supplier inventory models in supply chain management: A review", International Journal of Production Economics, Vol. 81/82, pp. 265-79.

Monczka, R.M., and Trecha, S.J. (1988), "Cost-based supplier performance evaluation", Journal of Purchasing and Materials Management, Vol. 24, No. 1, pp. 2-7.

Narasimhan, R., Talluri, S., and Mendez, D. (2001), "Supplier evaluation and rationalization via data envelopment analysis: an empirical examination", Journal of Supply Chain Management, Vol. 37, No. 3, pp. 28-37. 
Orlikowski, W.J. (1992), "The Duality of Technology: Rethinking the Concept of Technology in Organizations", Organization Science, Vol. 3, No. 3, pp. 398-426.

Orlikowski, W.J. (2000), “Using Technology and Constituting Structures: A Practice Lens for Studying Technology in Organizations", Organization Science, Vol. 11, No. 4, pp. 404-428.

Platts, K.W., and Song, N. (2010), "Overseas sourcing decisions-the total cost of sourcing from China", Supply Chain Management: An International Journal, Vol. 15, No. 4, pp. 320-331.

Ramanathan, R. (2007), "Supplier selection problem: integrating DEA with the approaches of total cost of ownership and AHP”, Supply Chain Management: An International Journal, Vol. 12, No. 4, pp. 258-261.

Ruiz-Torres, A.J., and Mahmoodi, F. (2007), "The optimal number of suppliers considering the costs of individual supplier failures", Omega, Vol. 35, No. 1, pp. 104-115.

Saen, R.F., 2006, “A decision model for selecting technology suppliers in the presence of nondiscretionary factors", Applied Mathematics and Computation, Vol. 181, No. 2, pp. 1609-1615.

Samson, D., and Terziovski, M. (1999), "The relationship between total quality management practices and operational performance", Journal of Operations Management, Vol. 17, pp. 393-409.

Sarkis, J., and Talluri, S. (2002), "A model for strategic supplier selection", Journal of Supply Chain Management, Vol. 38, No. 1, pp. 18-28.

Sawik, T. (2011), "Selection of supply portfolio under disruption risks", Omega, Vol. 39, No. 2, pp. 194-208.

Shin, H., Collier, D.A., and Wilson, D.D. (2000), "Supply management orientation and supplier/buyer performance", Journal of Operations Management, Vol. 18, No. 3, pp. 317-333.

Simon, H. (1957), "A Behavioral Model of Rational Choice", in Models of Man, Social and Rational: Mathematical Essays on Rational Human Behavior in a Social Setting. New York: Wiley.

Sklar, A. (1959), "Fonctions de répartition à n dimensions et leures marges", Publications de l'Institut de Statistique de L’Université de Paris, Vol. 8, pp. 229-231.

Talluri, S., and Narasimhan, R. (2004), "A methodology for strategic sourcing”, European Journal of Operational Research, Vol. 154, No. 1, pp. 236-50.

Talluri, S., DeCampos, H.A., and Hult, G.T.M. (2013), "Supplier rationalization: A sourcing decision model”, Decisions Science Journal, Vol. 44, No. 1, pp. 57-86.

Timmerman E. (1986), “An approach to vendor performance evaluation”, Journal of Purchasing and Supply Management, Vol. 1, pp. 2-8. 
Tone, K., and Tsutsui, M. (2010), "Dynamic DEA: a slacks-based measure approach", Omega, Vol. 38, No. 3, pp. 145-156.

Vakkuri, J., and Meklin, P. (2006), "Ambiguity in performance measurement: a theoretical approach to organisational uses of performance measurement", Financial Accountability \& Management, Vol. 22, No. 3, pp. 235-250.

Van den Abbeele, A., Roodhooft, F., and Warlop, L. (2009), "The effect of cost information on buyersupplier negotiations in different power settings", Accounting, Organizations and Society, Vol. 34, No. 2, pp. 245-266.

Van Weele, A.J. (2005), Purchasing and supply chain management: Analysis, strategy, planning and practice. Cengage Learning EMEA.

Visani F., Moeller K., and Silvi R., (2012), "Efficiency Measurement for Supplier Selection and Control: a Data Envelopment Analysis Approach", in Gregoriou G.N., Finch N. (eds), Best Practices in Management Accounting, Palgrave Macmillan (UK), pp. 133-145.

Weber, C.A., Current, J.R., and Benton, W.C. (1991), "Vendor selection criteria and methods", European Journal of Operational Research, Vol. 50, No. 1, pp. 2-18.

Weber, M., Hiete, M., Lauer, L., and Rentz, O. (2010), "Low cost country sourcing and its effects on the total cost of ownership structure for a medical devices manufacturer", Journal of Purchasing and Supply Management, Vol. 16, No. 1, pp. 4-16.

Wouters, M., Anderson, J.C., and Wynstra, F. (2005), “The adoption of total cost of ownership for sourcing decisions-a structural equations analysis", Accounting, Organizations and Society, Vol. 30, No. 2, pp. $167-$ 191.

Wu, T., and Blackhurst J. (2009), "Supplier evaluation and selection: an augmented DEA approach", International Journal of Production Research, Vol. 47, No.16, pp. 4593-4608.

Yeung, A.C.L. (2008), "Strategic supply management, quality initiatives, and organizational performance", Journal of Operations Managemement, Vol. 26, No. 4, pp. 490-502.

Zachariassen, F., and Arlbjørn, J.S. (2011), "Exploring a differentiated approach to total cost of ownership", Industrial Management \& Data Systems, Vol. 111, No. 3, pp. 448-469. 